\title{
Inhibition of Glycine Oxidation in Cultured Fibroblasts by Isoleucine
}

\author{
Righard E. Hillman, ${ }^{[13]}$ Luaille H. Sowers, and Jack L. Cohen \\ Division of Medical Genetics, Department of Pediatrics, Washington University School of Medicine, \\ St. Louis Children's Hospital, St. Louis, Missouri USA
}

\begin{abstract}
Extract
Cultured fibroblasts were shown to oxidize glycine to $\mathrm{CO}_{2}$. Isoleucine $(10 \mathrm{~mm})$ inhibited glycine oxidation to $\mathrm{CO}_{2}$ by about $60 \%$ in a concentration range of from 0.025 to $10 \mathrm{~mm}$ glycine in fibroblasts grown from a patient with $\beta$-ketothiolase deficienty. Glycine oxidation by control cell lines was not inhibited by isoleucine. These studies demonstrate an interrelation between isoleucine catabolism and glycine oxidation in fibroblasts cultured from a patient with the ketotic hyperglycinemia syndrome.

\section{Speculation}

Hyperglycinemia and hyperglycinuria seen in the "ketotic hyperglycinemia" syndrome would appear to be secondary to accumulation of products of isoleucine catabolism. Thus, the varying levels of glycine reported in the serum and urine of these patients probably reflect differences in protein and isoleucine intake than rather primary blocks in glycine metabolism.
\end{abstract}

\section{Introduction}

Since its original description by Childs et al. [2], the "ketotic hyperglycinemia" syndrome has been shown to be associated with three different defects in the pathway from isoleucine to succinyl-CoA. The sister of Childs' original patient was demonstrated to have propionyl-CoA carboxylase deficiency [4], other cases have been described with methylmalonyl-CoA mutase deficiency [8], and, recently, a patient was described who appeared to have $\beta$-ketothiolase deficiency [3]. All three of these defects have been associated with increased excretion of products in the isoleucine degradative pathway prior to propionyl-CoA. Tiglic acid was identified with propionyl-CoA carboxylase deficiency [7] and $\beta$-ketothiolase deficiency [3]. Butanone or $\alpha$-methylacetoacetate, or both together, have been found in association with propionyl-CoA carboxylase deficiency [6], methylmalonyl-CoA mutase deficiency [8], and $\beta$-ketothiolase deficiency [3]. $\alpha$-Methyl- $\beta$-hydroxybutyrate was found in the patient with $\beta$-ketothiolase deficiency [3].

There has never been a satisfactory explanation of the elevated levels of glycine in serum and urine of patients with these disorders of isoleucine metabolism. The high and sustained glycine elevation in the patient with $\beta$-ketothiolase deficiency prompted investigation of the interrelation between the isoleucine degradative pathway and glycine metabolism. These studies were carried out in cultured fibroblasts.

\section{Materials and Methods}

Skin biopsy explants from the patient and their subcultures were grown in nutrient medium $F-12$ [9] which contained $10 \%$ fetal calf serum, $30 \mathrm{~mm}$ HEPES, 
pH 7.6, penicillin, 100,000 U/liter, and streptomycin, $100 \mathrm{mg} /$ liter. This medium contains only $4 \mathrm{mg}$ isoleucine/liter. Fibroblasts were grown to confluency in Bellco roller bottles $\left(1,410 \mathrm{~cm}^{2}\right)$, harvested with $0.25 \%$ trypsin, washed twice with isotonic saline, and then centrifuged at $500 \times g$ before resuspension in the media used in the incubation studies.

Fibroblasts from three control patients were prepared in the same manner as the cells of the patient but were also grown in Eagle's minimum essential medium [9] which contains $52.5 \mathrm{mg}$ isoleucine/liter. As noted in a previous report [3], the fibroblasts of the patient could not be maintained in this relatively high isoleucine medium.

Incubation studies were carried out with cell suspensions which contained $0.5-1 \mathrm{mg}$ cell protein $/ \mathrm{ml} \mathrm{Krebs}$ phosphate buffer ( $\mathrm{pH}$ 7.4). The incubation tubes were gassed with $100 \%$ oxygen before sealing. Cells were incubated for $3 \mathrm{hr}$ at $37^{\circ}$. Glycine was added at the beginning of the incubation period in a concentration range of $0.025-10 \mathrm{~mm}$. All tubes contained $2.5 \mu \mathrm{Ci}$ of $\left(\mathrm{U}^{14} \mathrm{C}\right)$ glycine $[10]$. When the effects of isoleucine on glycine oxidation were studied, $10 \mathrm{~mm}$ isoleucine was added either $1 \mathrm{hr}$ before or concurrently with the incubation study. At the end of the incubation period the incubation tubes were placed in ice, $1 \mathrm{ml}$ NCS [11] was injected into a tube suspended above the incubation mixture to collect ${ }^{14} \mathrm{CO}_{2}$, and $1 \mathrm{ml} 6 \mathrm{~N} \mathrm{H}_{2} \mathrm{SO}_{4}$ was added to the incubation mixture. The tubes were left at room temperature (about $20^{\circ}$ ) for $2 \mathrm{hr}$ before duplicate samples of NCS were removed for counting in a liquid scintillation counter.

All results represent the mean \pm SEM of $8-12$ independent determinations.

\section{Results}

Over the range of glycine concentrations studied (0.025-10 mM), $10 \mathrm{~mm}$ isoleucine inhibited glycine oxidation by the fibroblasts of the patient by about $60 \%$ (Table I). Inhibition was observed whether the isoleucine was added at the same time as the glycine or $1 \mathrm{hr}$ before the glycine was added. However, the simultaneous addition of isoleucine and glycine produced greater variation in the degree of inhibition than did preincubation with this amino acid.

Oxidation was greater by the control cell lines than by the fibroblasts of the patient at all concentrations of glycine except $10 \mathrm{~mm}$ (Table II). Isoleucine did not inhibit glycine oxidation by fibroblasts grown from normal persons at any point in this concentration range.

Control cell lines grown in Eagle's minimal essential medium (52.5 $\mathrm{mg} /$ liter isoleucine) showed less than $10 \%$ of the glycine oxidation seen when the same cell lines were grown in medium $F-12$ (4 mg/liter). This dramatic difference emphasizes the need to use standard growth conditions to carry out reproduction of

Table I. Glycine oxidized $\left(10^{-12}\right.$ moles $\left./ 3 \mathrm{hr}\right)$ in fibroblasts grown from a patient with $\beta$-ketothiolase deficiency

\begin{tabular}{lccccr}
\hline \multicolumn{1}{c}{ Additions to media } & \multicolumn{3}{c}{ Initial glycine concentration, mM } \\
\cline { 2 - 5 } & 0.025 & 0.125 & 0.525 & 2.025 \\
\hline None & $32 \pm 4$ & $121 \pm 19$ & $511 \pm 45$ & $1,480 \pm 80$ & $10,800 \pm 1500$ \\
Isoleucine, $10 \mathrm{~mm}$; zero time & $14 \pm 2$ & $42 \pm 15$ & $230 \pm 50$ & $587 \pm 85$ & $3,300 \pm 1100$ \\
Inhibition, $\%$ & 56.8 & 65.1 & 55.0 & 60.2 & 69.4 \\
Isoleucine, $10 \mathrm{~mm}$; time $-60 \mathrm{~min}$ & $11 \pm 2$ & $34 \pm 6$ & $248 \pm 27$ & $547 \pm 58$ & $4,000 \pm 500$ \\
Inhibition, $\%$ & 65.0 & 72.1 & 51.3 & 62.9
\end{tabular}

${ }^{1}$ Fibroblasts were grown in nutrient medium $F-12$ containing $10 \%$ fetal calf serum. Cells were harvested with $0.25 \%$ trypsin and then suspended in Krebs phosphate buffer. Glycine was added at the beginning of a 3-hr incubation period. Results are corrected to a cell protein of $1 \mathrm{mg} / \mathrm{ml}$ and represent the mean \pm SEM of $8 \sim 12$ independent observations.

Table II. Glycine oxidized $\left(10^{-12}\right.$ moles $\left./ 3 \mathrm{hr}\right)$ in fibroblasts grown from normal persons ${ }^{1}$

\begin{tabular}{lccccc}
\hline \multirow{2}{*}{ Additions to media } & \multicolumn{4}{c}{ Initial glycine concentration, mm } \\
\cline { 2 - 5 } & 0.025 & 0.125 & 0.525 & 2.025 \\
\hline None & $40 \pm 10$ & $135 \pm 38$ & $813 \pm 94$ & $2,540 \pm 850$ & $10,600 \pm 2300$ \\
Isoleucine, $10 \mathrm{~mm}$; zero time & $37 \pm 7$ & $153 \pm 38$ & $716 \pm 92$ & $2,620 \pm 520$ & $13,900 \pm 2200$ \\
Isoleucine, $10 \mathrm{~mm}$; time $-60 \mathrm{~min}$ & $36 \pm 6$ & $169 \pm 33$ & $789 \pm 101$ & $2,530 \pm 510$ & $14,100 \pm 2700$ \\
\hline
\end{tabular}

${ }^{1}$ See Table I for details. 
studies of amino acid metabolism in cultured mammalian cells.

\section{Discussion}

Isoleucine had a profound effect on the oxidation of glycine to carbon dioxide by fibroblasts grown from a patient with an enzyme defect in the isoleucine degradative pathway. This effect was seen when the fibroblasts of the patient were subjected to only short term incubations with isoleucine. Inhibition was seen over a 400-fold range of glycine concentrations, $0.025-10 \mathrm{~mm}$. Glycine oxidation by normal fibroblasts was not inhibited by similar short term exposure.

The exact nature of the inhibitor substance is not clear from these studies. Isoleucine itself would not appear to be effective. This thesis is evidenced by the lack of inhibition of glycine metabolism by isoleucine in the control lines during short term incubation and is supported by the lack of hyperglycinemia or hyperglycinuria in patients with maple syrup urine disease. Because of their accumulation in all three of the enzyme deficiencies associated with hyperglycinemia, the last three products of isoleucine metabolism before propionate formation, tiglyl-CoA, $\alpha$-methyl- $\beta$-hydroxybutyryl-CoA, and $\alpha$-methylacetoacetyl-CoA, must be studied further.

However, even if one of these three products is the inhibitor, the mechanism of the inhibition is not clear. Although the data do not rule out competitive inhibition of glycine oxidation by isoleucine, simple competition between these amino acids seems unlikely. When the isoleucine concentration was kept constant and the glycine concentration was increased by 400 -fold, inhibition of glycine oxidation actually increased slightly, from 57 to $69 \%$, rather than decreased. Whether the inhibition represents a transport phenomenon, a direct inhibition of an enzyme in the glycine metabolic process, or some other mechanism requires further investigation.

Glycine oxidation in normal fibroblasts is influenced by growth conditions and was considerably reduced in cells cultured for several passages in Eagle's minimal essential medium. The mechanism of this decrease is presently unclear. However, these observations may explain the conclusion of Ando et al. [1] that glycine is not oxidized in cultured fibroblasts.

\section{Summary}

Isoleucine $(10 \mathrm{~mm})$ was found to inhibit glycine oxidation to $\mathrm{CO}_{2}$ over a concentration range from 0.025 to $10 \mathrm{~mm}$ in fibroblasts which were grown in a low isoleucine medium and which had been obtained from a patient with ketotic hyperglycinemia. No inhibition of glycine metabolism was seen in fibroblasts obtained from control subjects and grown in the same medium. These studies demonstrate an interrelation between isoleucine catabolism and glycine oxidation, but do not indicate the mechanism of the inhibition.

\section{References and Noles}

1. Ando, T., Klingberg, W. G., Ward, A. N., Rasmussfin, K. R., AND NyHAN, W. L.: Isovaleric acidemia presenting with altered metabolism of glycinc. Pediat. Res., 5: 478 (1971).

2. Childs, B., Nyhan, W. L., Borden, M., Bard, L., and Cooke, R. E.: Idiopathic hyperglycinemia and glycinuria: $A$ new disorder of amino acid metabolism. Pediatrics, 27: 522 (1961).

3. Hillman, R. E., And Keating, J. P.: Beta-ketothiolase deficiency as a cause of the "Ketotic Hyperglycinemia Syndrome." Pedialrics (in press).

4. Hsia, Y. E., Scul.t. K. J., And Rosenberg, L. E.: Defective propionate carboxylation in ketotic hyperglycinemia. Lancet, $i: 757$ (1969).

5. Keating, J. P., Feigin, R. D., Tenenbaum, S. M., and Hillman, R. E.: Hyperglycinemia with ketosis due to a defect in isoleucine metabolism: A preliminary report. Pediatrics, 50: 890 (1972).

6. MeNkes, J. H.: Idiopathic hyperglycinemia: Isolation and identification of three previously undescribed urinary ketones. J. Pediat., 69: 413 (1966).

7. Nyhan, W. L., Ando, T., Rasmussen, K., Wadlington, W., Kilroy, A. W., Cotrom, D., ANd Hull, D.: Tiglicaciduria in propionicacidaemia. Biochem. J., 126: 1035 (1972).

8. Rosenberg, L. E., Lilljeqvist, A. C., and Hsia, Y. E.: Methylmalonic acidemia: An inborn error leading to metabolic acidosis, long chain ketonuria, and intermittent hyperglycinuria. New Engl. J. Med., 278: 1319 (1968).

9. Grand Island Biological Company, Chagrin Falls, Ohio.

10. New England Nuclear Corporation, Boston, Mass.

11. Nuclear Chicago Corporation, Des Plaines, Ill.

12. This work was supported in part by United States Public Health Service Grant no. AM 15531-02 and a Ranken Jordan Center grant. The authors wish to thank Miss Elaine $F$. Otto for her technical assistance and Mrs. Sabra Lovejoy for her patience in typing this manuscript.

13. Requests for reprints should be addressed to: Rrcmird E. Hillman, M.D., Division of Medical Genetics, Department of Pediatrics, Washington University School of Medicine, St. Louis Children's Hospital, St. Iouis, Mo. 63110 (USA).

14. Accepted for publication July 19, 1973. 